\title{
ASSOCIATION OF NEUROPEPTIDE S RECEPTOR 1 AND GLUTAMATE DECARBOXYLASE 1 GENE POLYMORPHISMS WITH POSTTRAUMATIC STRESS DISORDER
}

\author{
Shpend Haxhibeqiri ${ }^{1}$, Valdete Haxhibeqiri ${ }^{2}$, Ferid Agani $^{3}$, Aferdita Goci Uka ${ }^{4}$, Blerina Hoxha ${ }^{4}$, \\ Alma Dzubur Kulenovic ${ }^{5}$, Abdulah Kučukalić ${ }^{5}$, Esmina Avdibegović ${ }^{6}$, Osman Sinanović ${ }^{6}$, \\ Dragan Babic ${ }^{7}$, Miro Jakovljevic ${ }^{8}$, Sabina Kučukalić ${ }^{5}$, Alma Bravo Mehmedbašićs, Nermina Kravić ${ }^{6}$, \\ Mirnesa Muminović-Umihanić ${ }^{6}$, Romana Babić ${ }^{7}$, Marko Pavlović ${ }^{7}$, Nenad Jakšić ${ }^{8}$, \\ Branka Aukst Margetić ${ }^{9}$, Duško Rudan ${ }^{8}$, Elma Ferić Bojićc ${ }^{10}$, Damir Marjanović ${ }^{10}$, Christiane Ziegler ${ }^{11}$, \\ Christiane Wolf ${ }^{12}$, Bodo Warrings ${ }^{12}$, Katharina Domschke ${ }^{11}$ \& Jürgen Deckert ${ }^{12}$ \\ ${ }^{1}$ Institute of Kosovo Forensic Psychiatry, University Clinical Centre of Kosovo, Prishtina, Kosovo \\ ${ }^{2}$ Department of Clinical Biochemistry, University Clinical Centre of Kosovo, Prishtina, Kosovo \\ ${ }^{3}$ Faculty of Medicine, University Hasan Prishtina, Prishtina, Kosovo \\ ${ }^{4}$ Department of Psychiatry, University Clinical Centre of Kosovo, Prishtina, Kosovo \\ ${ }^{5}$ Department of Psychiatric, Clinical Centre University of Sarajevo, Sarajevo, Bosnia and Herzegovina \\ ${ }^{6}$ Department of Psychiatry, University Clinical Centre Tuzla, Tuzla, Bosnia and Herzegovina \\ ${ }^{7}$ Department of Psychiatry, University Clinical Centre of Mostar, Mostar, Bosnia and Herzegovina \\ ${ }^{8}$ Department of Psychiatry, University Hospital Centre Zagreb, Zagreb, Croatia \\ ${ }^{9}$ Department of Psychiatry, University Hospital Centre Sestre Milosrdnice, Zagreb, Croatia \\ ${ }^{10}$ Department of Genetics and Bioengineering International Burch University, Sarajevo, Bosnia and Herzegovina \\ ${ }^{11}$ Department of Psychiatry and Psychotherapy, Medical Center - University of Freiburg, \\ Faculty of Medicine, University of Freiburg, Germany \\ ${ }^{12}$ Department of Psychiatry, Psychosomatics and Psychotherapy, \\ Center of Mental Health, University Hospital of Würzburg, Würzburg, Germany
}

received: 4.2.2019;

revised: 10.5.2019;

accepted: 22.5.2019

\section{SUMMARY}

Background: Posttraumatic stress disorder (PTSD) is an anxiety disorder caused by highly traumatic experiences. The aim of this study was to investigate the influence of single nucleotide polymorphisms (SNPS) in the neuropeptide S receptor 1 (NPSR1) and the glutamate decarboxylase 1(GAD1) gene on PTSD and its psychopathological aspects among individuals affected by the Balkan wars during the 90 s.

Subjects and methods: This study was conducted as part of the South Eastern Europe (SEE) study on molecular mechanisms of PTSD. It comprised 719 participants (539 males), including those with current PTSD, remitted PTSD and healthy volunteers. Psychometric evaluation was performed using the Mini International Neuropsychiatric Interview (M.I.N.I.), the Clinician Administrated PTSD Scale (CAPS) andthe Brief Symptom Inventory (BSI). We examined NPSR1 single nucleotide polymorphism (SNP) rs324981 and GAD1 variant rs3749034 genotypes. Case-control analyses were carried out using logistical regression to determine genotype differences between all patients that had either current or remitted PTSD and control individuals. To analyse the influence of the analysed SNPS on PTSD severity, we performed linear regression analyses with CAPS and BSI within each of the two patient groups separately. All of the calculations were performed for additive allelic, recessive, dominant and genotypic models.

Results: We observed a nominally significant association for the major allele (G) of GAD1 rs3749034 with an increased risk to develop PTSD in a case control analysis in the recessive model $(P=0.0315$, odds ratio=0.47, $S E=0.35)$. In contrast, a nominally significant association of the minor allele (A) with higher CAPS scores was identified within the patient group with lifetime PTSD in the dominant model $(P=0.0372, \beta=6.29, S E=2.99)$. None of these results did withstand correction for multiple tests. No nominal significant results of GAD1 rs3749034 were found with regard to the intensity of psychological BSI symptoms. Case-control analyses of NPSR1 rs324981 revealed a nominally significant higher risk for homozygous T allele carriers to develop PTSD (P=0.0452) in the recessive model. On the other hand, the T allele showed a nominally significant association with higher BSI scores in patients suffering from lifetime PTSD in the recessive model $(P=0.0434)$. Again, these results were not significant anymore after correction for multiple tests. No associations of NPSR1 rs324981 and CAPS score was identified.

Conclusion: The findings of this study provide some evidence that the NPSR1 and GAD1 polymorphisms might play a role in the development of war-related PTSD and its related psychological expressions. Further research is needed to elucidate the interactions of specific gene variants and environmental factors in the development of PTSD.

Key words: PTSD - NPSR1 - GAD1 - gene polymorphism - war trauma 


\section{INTRODUCTION}

Posttraumatic stress disorder (PTSD) occurs in individuals exposed to traumatic events (e.g., life-threatening accidents, rape, military combat), and includes four groups of symptoms: intrusive re-experiencing of trauma, avoidance of stimuli associated with the trauma, negative cognitions and mood associated with the trauma, and excessive psychophysiological reactivity (American Psychiatric Association 2013). The etiology of PTSD is complex and multifactorial, with an interaction between various environmental and genetics factors (Breslau \& Kessler 2001, Domschke 2012, Jakovljević 2012).

Chronic PTSD is linked to considerable comorbidity, mortality, and disability during daily activities (Brunello et al. 2001, Gillespie et al. 2009, Weiss et al. 2011). While $50-85 \%$ of Americans experience a traumatic event during their lifetime, only a minority of these individuals (5-7\%) develop PTSD (Kessler \& Wang 2008). Twin studies related to PTSD have addressed the complex genetic relationship between exposure to trauma and disorder risk. Over the last years, there has been an increased interest in identifying genes that increase the risk for PTSD or predict treatment outcome (Sheerin et al. 2017). Because of the phenotypic heterogeneity and complexity of defining PTSD for the purposes of genetic studies, many analyses rely on intermediate phenotypes (Meyer-Lindenberg \& Weinberger 2006) or endophenotypes (Gottesman \& Gould 2003), which are conceptualized as being more directly related to relevant gene action.

Dysfunction of the gamma-aminobutyric (GABA) system has been proposed as a major neurobiological pathomechanism of anxiety, including PTSD (Domschke \& Zwanzger 2008, Nemeroff 2003, Roy-Byrne 2005, Zwanzger \& Rupprecht 2005). The key enzyme for the synthesis of the inhibitory and anxiolytic neurotransmitter gamma-aminobutyric acid (GABA), is supposed to influence various mental disorders, including mood and anxiety disorders. Genetic variants of glutamate decarboxylase 1 (GAD1) have been linked to mood symptoms (Lundorf et al. 2005) and panic disorder (Weber et al. 2012). For example, Weber et al. (2012) found an association between GAD1 single nucleotide polymorphisms (SNPs) and panic disorder symptoms, although only among female participants. Similar findings were obtained in a mixed anxiety (including panic disorder) and mood disorder sample (Hettema et al. 2006). With regard to PTSD, only one recent preliminary study documented a significant association between GAD1 polymorphisms and more pronounced PTSD symptoms among American combat veterans (Bountress et al. 2017). However, this preliminary work was based on the genetic risk sum score (GRSS), so no information is available for individual SNPs.

Neuropeptide S receptor1 (NPSR1) encodes a member of the vasopressin/oxytocin subfamily of $\mathrm{G}$ protein- coupled receptors. The encoded membrane protein acts as a receptor for neuropeptide $S$ and affects a variety of cellular processes through its signaling. Based on previous animal and molecular genetic studies, neuropeptide $\mathrm{S}$ has been suggested to play a crucial role in the pathogenesis of stress, arousal and anxiety (Vitale et al. 2008, Xu et al. 2004). Moreover, Domschke et al. (2011) have shown an association of the T allele of the NPSR1 SNP rs324981 with panic disorder among female patients, as well as with elevated anxiety sensitivity and increased heart rate during a behavioral avoidance test. In addition, NPSR1 genotypes also influence explicit anxiety ratings through their interaction with stressful life events (Glotzbach-Schoon et al. 2013). Thus, previous research suggests that the $\mathrm{T}$ allele of the NPSR1 SNP rs324981 (Domschke et al. 2011, Pape et al. 2010, Racz$\mathrm{ka}$ et al. 2010) represents a vulnerability factor for the development of anxiety disorders, presumably as a result of facilitated fear conditioning (Mineka \& Oehlberg 2008, Orr et al. 2000). However, no studies have been carried out on combat veterans suffering from PTSD.

Given the literature on the involvement of common genetic variants of GAD1 and NPSR1 in stress-related and anxiety disorders, the general aim of this research was to investigate the influence of GAD1 and NPSR1 SNPs on combat-related PTSD, its psychopathological aspects and related coping strategies.

\section{SUBJECTS AND METHODS}

\section{Subjects}

This research was conducted as part of the South Eastern Europe (SEE)-PTSD study on "Molecular mechanisms of posttraumatic stress disorder" (see Džubur Kulenović et al. 2016). The study was carried out at five psychiatric research centres in Bosnia and Herzegovina (Sarajevo, Mostar, Tuzla), Croatia (Zagreb), and the Republic of Kosovo (Pristina). These are countries whose population has experienced severe war-related trauma between 1991 and 1999. Recruitment of patients and controls began in 2013 and was completed by the end of 2015. The general inclusion criteria were that participants were at the time of traumatization at least 16 years of age and not older than 65 years at time of recruitment. The exclusion of subjects who survived trauma in childhood was based on the frequently described difference in both clinical presentation and course of PTSD and other psychiatric disorders occurring after trauma exposure at young age (Nemeroff 2016). Other exclusion criteria were: the presence of organic depression, epilepsy, psychotic symptoms, addiction (except smoking), intellectual disability, oncological disorders, valproid acid use and $1^{\text {st }}$ and $2^{\text {nd }}$ degree relation to an already recruited person.

Of 747 recruited individuals, finally 719 participants (mean age $49.4 \pm 7.9 ; 487$ males) could be included in this study. Of those 218 participants (mean age 50.1 \pm 6.7 ; 
157 males) suffered from current PTSD, 151 participants had lifetime PTSD (mean age 49.5 $\pm 8.2 ; 98$ males) and 350 healthy volunteers showed no diagnosable PTSD (mean age $48.8 \pm 8.5 ; 232$ males) symptoms. Additional details about the study design, recruitment, gender distribution, methodology of blood collection and procedures of storing and transporting were described in our previous paper (Džubur Kulenović et al. 2016).

\section{Ethical Votes}

Ethical votes were obtained at each of the participating clinical center and participants gave their written informed consent according to the principles of the Helsinki declaration (WMA 2013).

\section{Psychometric methods}

Interviews were performed by trained medical personnel (psychiatrists, clinical psychologists or psychiatric residents). The presence or absence of PTSD symptoms in the screening stage was assessed using a structured clinical interview - Mini International Neuropsychiatric Interview (M.I.N.I.). The Clinician Administrated PTSD Scale (CAPS) (Blake et al. 1996) was performed to make a categorical PTSD diagnosis (current or remitted PTSD) and to assess the severity of PTSD symptoms. And finally the Brief Symptom Inventory (BSI) (Derogatis \& Melisaratos 1983) was applied to provide information on the severity of general psychiatric symptoms.

\section{Molecular Analyses}

For genotyping, genomic DNA was isolated from frozen venous blood by using the FlexiGene DNA Kit (Qiagen, Hilden, Germany) according to manufacturer's instructions and stored until use at the Laboratory of the Department of Psychiatry, Psychosomatics and Psychotherapy in Würzburg, at $-80^{\circ} \mathrm{C}$. The GAD1 SNP rs3749034 was genotyped by means of a custom designed KASP genotyping assay (LGC, Berlin, Germany). PCR reaction including an end-point fluorescent readout was performed according to manufacturers' instructions in a CFX384 Touch Cycler (Biorad, Munich, Germany). Genotypes were determined by using the CFX Manager Software. The functional variant NPSR1 rs324981 was genotyped according to already published protocols (see Domschke et al. 2011).

\section{Statistical analyses}

Statistical analyses were performed using PLINK 1.9. Both variants GAD1 rs3749034 and NPSR1 rs324981 were polymorphous (minor allele frequency $>20 \%$ ), reached a minimal genotyping call rate of $96 \%$ and did not deviate from Hardy-Weinberg equilibrium ( $p>0.05$ after Bonferroni correction). Logistic regression was used for case-control analyses in which both patient groups were analyzed jointly versus the control individuals. Within the two groups of patients, i.e. individuals with current or lifetime PTSD, linear regression was carried out for the dimensional CAPS and BSI scores, respectively. The following models were tested in all phenotypes: additive allelic, dominant and recessive, as well as the genotypic model. The significance level was Bonferroni adjusted for 23 variants that were analyzed in total in the entire project $(\alpha=0.002)$ as already described by Džubur Kulenović et al. (2016). The level of significance was set at $\mathrm{P} \leq 0.05$ (two-tailed) for all the analyses.

\section{RESULTS}

In this study we investigated first in a case-control approach $(\mathrm{N}=719)$ the role of the two known polymorphisms GAD1 rs3749034 and NPSR1 rs324981, on the development of a PTSD and characterized in a second step the influence of allelic variation on PTSD linked CAPS and BSI total scores individually in all cases who suffered either from current PTSD ( $\mathrm{N}=211$ for GAD 1 and 215 for NPSR1) or lifetime PTSD ( $\mathrm{N}=148$ for GAD1 and 150 for NPSR1) symptoms.

\section{GAD1 rs3749034 polymorphism}

Categorical analyses of GAD1 rs3749034 reached nominal significance in the recessive model $(\mathrm{P}=0.0315$, odds ratio $=0.47, \mathrm{SE}=0.35$ ) (Table 1 ) with the major allele $(G)$ representing the risk allele. With regard to the CAPS phenotype we obtained not in the current, but in the lifetime PTSD group a nominal association in the dominant model $(\mathrm{P}=0.0372, \beta=6.29, \mathrm{SE}=2.99)$ (Table 1 and Figure 1), where carriers of the minor (A) allele

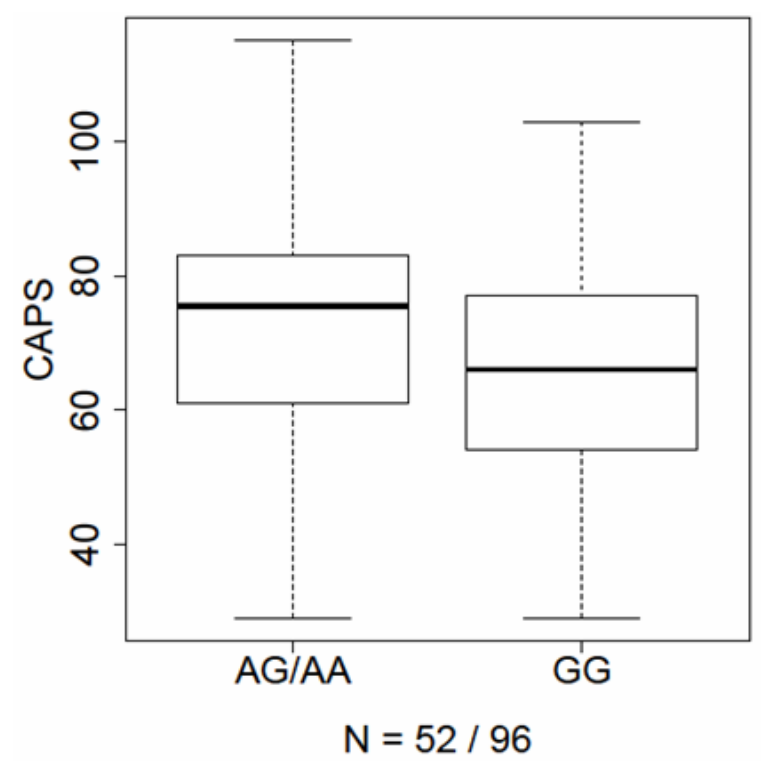

Figure 1. Scores on the CAPS among lifetime PTSD participants, for the GAD1 rs3749034 genotypes $(\mathrm{P}=0.037)$ in the dominant model 
Table 1. Association results of GAD1 rs3749034, along with genotype- and allele counts, for individuals in analysis, CAPS and BSI means and standard deviations (SD), as well as nominal p-values of regression analyses

\begin{tabular}{|c|c|c|c|c|c|c|c|c|c|}
\hline \multirow{2}{*}{ GAD1 rs3749034 } & \multicolumn{2}{|c|}{ Allelic Model } & \multicolumn{3}{|c|}{ Genotypic Model } & \multicolumn{2}{|c|}{ Dominant Model } & \multicolumn{2}{|c|}{ Recessive Model } \\
\hline & $\mathrm{A}$ & $\mathrm{G}$ & AA & AG & GG & $\mathrm{AA} / \mathrm{AG}$ & GG & AA & $\mathrm{AG} / \mathrm{GG}$ \\
\hline Controls & 153 & 523 & 25 & 103 & 210 & 128 & 210 & 25 & 313 \\
\hline PTSD $_{\text {lifetime }}$ & 57 & 239 & 5 & 47 & 96 & 52 & 96 & 5 & 143 \\
\hline PTSD $_{\text {current }}$ & 77 & 345 & 8 & 61 & 142 & 69 & 142 & 8 & 203 \\
\hline$P_{\text {case-control-value }}$ & \multicolumn{2}{|c|}{0.0778} & \multicolumn{3}{|c|}{0.0889} & \multicolumn{2}{|c|}{0.2516} & \multicolumn{2}{|c|}{0.0315} \\
\hline $\mathrm{CAPS}_{\text {lifetime }}($ mean $\pm \mathrm{SD})$ & $70.7 \pm 19.1$ & $66.0 \pm 17.1$ & $64.4 \pm 14.5$ & $72.1 \pm 19.7$ & $64.6 \pm 16.0$ & $71.3 \pm 19.4$ & $64.6 \pm 16.0$ & $64.4 \pm 14.5$ & $67,0 \pm 17.7$ \\
\hline $\mathrm{P}_{\mathrm{CAPS}}$-value & \multicolumn{2}{|c|}{0.0945} & & 0.0703 & & \multicolumn{2}{|c|}{0.0372} & \multicolumn{2}{|c|}{0.7063} \\
\hline $\mathrm{CAPS}_{\text {current }}($ mean $\pm \mathrm{SD})$ & $80.5 \pm 23.8$ & $79.0 \pm 20.1$ & $85.5 \pm 26.2$ & $79.2 \pm 23.0$ & $78.9 \pm 19.5$ & $79.9 \pm 23.5$ & $78.9 \pm 19.5$ & $85.5 \pm 26.2$ & $79.0 \pm 20.5$ \\
\hline $\mathrm{P}_{\mathrm{CAPS}}$-value & \multicolumn{2}{|c|}{0.5823} & & 0.6932 & & \multicolumn{2}{|c|}{0.7621} & \multicolumn{2}{|c|}{0.3931} \\
\hline $\mathrm{BSI}_{\text {lifetime }}($ mean $\pm \mathrm{SD})$ & $66.9 \pm 43.2$ & $75.0 \pm 50.6$ & $42.8 \pm 10.8$ & $72.3 \pm 45.8$ & $75.6 \pm 51.6$ & $69.3 \pm 44.5$ & $75.6 \pm 51.6$ & $42.8 \pm 10.8$ & $74.5 \pm 49.8$ \\
\hline $\mathrm{P}_{\mathrm{BSI}}$-value & \multicolumn{2}{|c|}{0.2579} & \multicolumn{3}{|c|}{0.3295} & \multicolumn{2}{|c|}{0.4454} & \multicolumn{2}{|c|}{0.1529} \\
\hline $\mathrm{BSI}_{\text {current }}($ mean $\pm \mathrm{SD})$ & $112.6 \pm 49.0$ & $112.7 \pm 45.5$ & $103.8 \pm 52.6$ & $115.1 \pm 47.7$ & $112.3 \pm 45.1$ & $113.7 \pm 48.4$ & $112.3 \pm 45.1$ & $103.8 \pm 52.6$ & $113.1 \pm 45.9$ \\
\hline $\mathrm{P}_{\mathrm{BSI}}$-value & \multicolumn{2}{|c|}{0.8093} & \multicolumn{3}{|c|}{0.8097} & \multicolumn{2}{|c|}{0.9789} & \multicolumn{2}{|c|}{0.5290} \\
\hline
\end{tabular}

GAD1 - glutamate decarboxylase 1; PTSD - posttraumatic stress disorder; CAPS - Clinician Administered PTSD Scale;

BSI - Brief Symptom Inventory; Italics indicates $p \leq 0.05$

Table 2. Association results of NPSR1 rs324981, along with genotype- and allele counts, for individuals in analysis, CAPS and BSI means and standard deviations (SD), as well as nominal P-values of regression analyses

\begin{tabular}{|c|c|c|c|c|c|c|c|c|c|}
\hline \multirow{2}{*}{ NPSR1 rs324981 } & \multicolumn{2}{|c|}{ Allelic Model } & \multicolumn{3}{|c|}{ Genotypic Model } & \multicolumn{2}{|c|}{ Dominant Model } & \multicolumn{2}{|c|}{ Recessive Model } \\
\hline & $\mathrm{T}$ & A & TT & TA & AA & TT/TA & AA & TT & TA/AA \\
\hline Controls & 331 & 357 & 72 & 187 & 85 & 259 & 85 & 72 & 272 \\
\hline PTSD $_{\text {lifetime }}$ & 155 & 145 & 40 & 75 & 35 & 115 & 35 & 40 & 110 \\
\hline PTSD $_{\text {current }}$ & 218 & 212 & 60 & 98 & 57 & 158 & 57 & 60 & 155 \\
\hline$P_{\text {case-control-value }}$ & \multicolumn{2}{|c|}{0.2577} & \multicolumn{3}{|c|}{0.0935} & \multicolumn{2}{|c|}{0.8787} & \multicolumn{2}{|c|}{0.0452} \\
\hline $\mathrm{CAPS}_{\text {lifetime }}($ mean $\pm \mathrm{SD})$ & $66.8 \pm 17.8$ & $67.0 \pm 17.4$ & $65.9 \pm 14.6$ & $68.1 \pm 19.9$ & $65.2 \pm 15.1$ & $67.3 \pm 18.3$ & $65.2 \pm 15.1$ & $65.9 \pm 14.6$ & $67.3 \pm 18.5$ \\
\hline $\mathrm{P}_{\text {CAPS-value }}$ & \multicolumn{2}{|c|}{0.9060} & \multicolumn{3}{|c|}{0.6968} & \multicolumn{2}{|c|}{0.5499} & \multicolumn{2}{|c|}{0.7054} \\
\hline $\mathrm{CAPS}_{\text {current }}($ mean $\pm \mathrm{SD})$ & $78.1 \pm 21.0$ & $80.4 \pm 20.7$ & $77.6 \pm 22.8$ & $78.7 \pm 18.6$ & $82.1 \pm 22.3$ & $78.3 \pm 20.3$ & $82.1 \pm 22.3$ & $77.6 \pm 22.8$ & $79.8 \pm 20.0$ \\
\hline $\mathrm{P}_{\mathrm{CAPS}}$-value & \multicolumn{2}{|c|}{0.2511} & \multicolumn{3}{|c|}{0.4758} & \multicolumn{2}{|c|}{0.2389} & \multicolumn{2}{|c|}{0.4669} \\
\hline $\mathrm{BSI}_{\text {lifetime }}($ mean $\pm \mathrm{SD})$ & $77.8 \pm 50.6$ & $68.7 \pm 47.7$ & $87.0 \pm 50.5$ & $67.7 \pm 48.8$ & $69.5 \pm 46.8$ & $74.5 \pm 50.2$ & $69.5 \pm 46.8$ & $87.0 \pm 50.5$ & $68.4 \pm 48.0$ \\
\hline $\mathrm{P}_{\mathrm{BSI}}-$ value & \multicolumn{2}{|c|}{0.1198} & \multicolumn{3}{|c|}{0.1246} & \multicolumn{2}{|c|}{0.6132} & \multicolumn{2}{|c|}{0.0434} \\
\hline $\mathrm{BSI}_{\text {current }}($ mean $\pm \mathrm{SD})$ & \multicolumn{2}{|c|}{$\begin{array}{c}113.4 \pm 45.9112 .3 \pm 46.5 \\
0.8728\end{array}$} & \multicolumn{3}{|c|}{$4 \pm 45.7 \quad 112.2 \pm 46.11$} & \multirow{2}{*}{\multicolumn{2}{|c|}{07944}} & \multicolumn{2}{|c|}{$.4 \pm 45.7 \quad 112.1 \pm 46.3$} \\
\hline $\mathrm{P}_{\mathrm{BSI}}$-value & \multicolumn{2}{|c|}{0.8728} & \multicolumn{3}{|c|}{0.9614} & & & \multicolumn{2}{|c|}{0.9986} \\
\hline
\end{tabular}

NPSR1- neuropeptide S receptor 1; PTSD - posttraumatic stress disorder; CAPS - Clinician Administered PTSD Scale;

BSI - Brief Symptom Inventory; $\quad$ Italics indicates $p \leq 0.05$

showed nominal significantly higher average CAPS scores than others. Neither in the current nor in the lifetime PTSD sample significant differences between the genotypes with regard to the intensity of psychological BSI symptoms were identified $\left(\mathrm{P}_{\mathrm{all}}>0.1\right)$ (Table 1).

\section{NPSR1 rs324981 polymorphism}

Case-control analyses of NPSR1 rs324981 revealed in the recessive model a nominally significant higher risk for homozygous $\mathrm{T}$ allele carriers to develop PTSD $(\mathrm{P}=0.0452)$ (Table 2). Within the other models no impact on the categorical phenotype of PTSD was detectable $(\mathrm{P}>0.05)$ (Table 2). When tests where run for the dimensional CAPS and BSI total scores, a nominally significant association was found for BSI in patients suffering from lifetime PTSD (recessive model: $\mathrm{P}=0.0434,18.70, \mathrm{SE}=9.17$ ) (Table 2), with the $\mathrm{T}$ allele conveying genetic risk. However, results for the BSI questionnaire could not be replicated in patients with diagnosed current PTSD ( $\left.\mathrm{P}_{\mathrm{all}}>0.05\right)$ (Table 2). Ana- lyses on CAPS total scores revealed neither for the current nor for the lifetime PTSD group any association $\left(\mathrm{P}_{\mathrm{all}}>0.05\right)$ (Table 2$)$.

\section{DISCUSSION}

To the best of our knowledge, this multicenter study was the first to assess the associations of the GAD1 rs3749034 and NPSR1 rs324981 polymorphisms with war-related PTSD and its accompanying psychological disturbances among the population of the Balkan war survivors. There were found nominal significant differences in the risk of PTSD development in the overall recessive model for the GAD1 rs3749034 polymorphism. With regard to the CAPS phenotype in the lifetime PTSD group, we obtained a significant result in the dominant model. With regard to PTSD, only one recent preliminary study documented a significant association between GAD1 polymorphisms and more pronounced PTSD symptoms among American combat veterans 
(Bountress et al. 2017). However, this preliminary work was based on the genetic risk sum score (GRSS), so no information is available for individual SNPs.

There were nominally significant differences in the risk of PTSD development in the overall case-control recessive model for the NPSR1 polymorphism, where homozygous $\mathrm{T}$ allele carriers are more enriched in those suffering from PTSD compared to those without PTSD which suggests a predisposition to an increased risk for PTSD development. Considering that the T allele carriers have a higher risk for panic disorder (Domschke et al. 2011), increased prefrontal activation in response to a threatening context, this result is supportive of the results of Domschke et al. (2011).

In the lifetime PTSD group, we found the NPSR1 rs324981 TT genotype to be associated with increased BSI scores. These findings are in line with the study conducted by Glotzbach-Schoon et al. (2013) who demonstrated the influence of the NPSR1 genotype on explicit anxiety ratings through its interaction with stressful life events. In addition, our results confirm previous research showing that the $T$ allele of the NPSR1 rs324981 polymorphism (Pape et al. 2010, Raczka et al. 2010) represents a vulnerability factor for the development of anxiety disorders, presumably as a result of facilitated fear conditioning (Mineka \& Oehlberg 2008).

Inconsistent results from candiate gene studies are seen frequently in neuropsychiatric research. Although it is a widely performed approach (Smoller 2016), the results of candidate gene analyses are subject to many factors that may cause bias and lead to contradictory conclusions (Cornelis et al. 2010, Koenen et al. 2008, Koenen et al. 2013, Goenjian et al. 2012). Further, this study had several methodological limitations. The patient cohort is fairly small, in particular when it is separated into remitted/lifetime PTSD and current PTSD which may have reduced statistical power. Studies in consortia such as the PGC consortia are therefore necessary. With regard to previous studies, the genetic background of our study population differed and may have had influence on our results. Also, trauma type is significantly different among individuals in this study, as the characteristics of the war situation differed between the countries and regions. This may have affected epigenetic processes which have confounded the genetic analyses. Another issue is the comorbidity with neuropsychiatric disorders which does not allow for conclusions regarding the specificity of the present findings to PTSD. However, even contradictory results may still support a general involvement of a gene in a particular disorder (Cornelis et al. 2010).

\section{CONCLUSION}

In conclusion, the results of this study provide some evidence that NPSR1 and GAD1 polymorphisms might play a role in the development and symptomatic expression of war-related PTSD. It will be of interest to examine additional SNPs in genes involved in the regu- lation of NPSR1 and GAD1 expression. As specific genes can facilitate the occurrence of certain psychiatric disorders, including war-related PTSD, the findings of this study could further inform our understanding of the complex pathophysiology of PTSD in the framework of the stress-diathesis or vulnerability-resilience model (Jakovljevic et al. 2012, 2017).

\section{Acknowledgements:}

We thank all the participants and their families without whose idealistic and enthusiastic support the study would not have been possible. We also would like to thank at Sarajevo: the Association of Women Victims of War and Bakira Hasecic, the Association of Physically Handicapped, Zilko Buljugija, Zoran Budimlija, MD, PhD, Jasminka Krehic, MD, PhD, Elvira Sabanovic, RSN and Subhija Gusic; in Kosovo: Feride Rushiti, MD, Selvije Izeti, MSc, Vjosa Devaja, MD, Melita Kallaba, MD from Kosova Rehabilitation Center for Trauma Survivors- KRCT; Emirjeta Kumnova, Veprore Shehu from Medica Kosova; Zahrije Podrimqaku Subashi from the Association of Political Prisoners, Kadire Tahiraj from the Center for Promotion of Women's Rights; Arbërore Ulaj, MD, Teuta Haxhiu, MD and Drita Gashi, MD, for their assistance in recruiting and interviewing participants; at Zagreb: Mirica Mavracic, Zoran Bradas, Zrinka Mirkovic and Maja Mezak Herceg for technical assistance in drawing blood and extracting DNA; at Tuzla: the staff of the Department of Transfusion of University Clinical Center of Tuzla, and the staff of the Department of Psychiatry, in particular Emina Hujdur, Medin Omerašević and Avdo Šakušić, MD for technical support and Maja Brkić and Sandra Zornić for their assistance in data collection; at Würzburg: Carola Gagel for technical assistance with extracting DNA. Thanks are highly deserved by and gratefully extended to Peter Riederer as spiritus rector who brought the consortium together. The study was funded by the DAAD program Stability Pact for South Eastern Europe and supported by the DFG-funded RTG 1253 (speaker Pauli) as well as the DFG-funded CRC-TRR58 (projects C02 Domschke, Deckert, and Z02 Deckert, Domschke).

\section{Conflict of interest: None to declare.}

\section{Contribution of individual authors:}

Each author has actively participated in the international research project (see Acknowledgments) and, therefore, has substantially contributed to the development and publication of this manuscript.

\section{References}

1. American Psychiatric Association: Diagnostic and Statistical Manual of Mental Disorders: DSM-5. Arlington, VA, APA, 2013

2. Amstadter AB, Koenen KC, Ruggiero KJ, Acierno $R$, Galea S, Kilpatrick DG et al: Variant in RGS2 moderates posttraumatic stress symptoms following potentially traumatic event exposure. J Anxiety Disord 2009; 23:369-373

3. Blake DD, Weathers FW, Nagy LM, Kaloupek DG, Gusman FD, Charney DS \& Keane TM: The development of a clinician-administered PTSD scale. J Trauma Stress 1995; 8:75-90

4. Bountress K, Sheerin C, Amstadter AB, Mandel H, Voltin $J$ \& Wang Z: The relation between GADI and PTSD symptoms: Shared risk for depressive symptoms. Psychiatry Res 2017; 258:607-608 
5. Brunello N, Davidson JR, Deahl M, Kessler RC, Mendlewicz J, Racagni $G$ et al: Post-traumatic stress disorder: diagnosis and epidemiology, comorbidity and social consequences, biology and treatment. Neuropsychobiology 2001; 43:150-162

6. Breslau $N$ \& Kessler RC: The stressor criterion in DSM$I V$, posttraumatic stress disorder: An empirical investigation. Biol Psychiatry 2001; 50:699-704

7. Canli $T$ \& Lesch KP: Long story short: the serotonin transporter in emotion regulation and social cognition. Nat Neurosci 2007; 10:1103-1109

8. Cornelis MC, Nugent NR, Amstadter AB, \& Koenen KC: Genetics of post-traumatic stress disorder: Review and recommendations for genome-wide association studies. Curr Psychiatry Rep 2010; 12:313-326

9. Derogatis L\& Melisaratos N: The Brief Symptom Inventory: A introductory report. Psychol Med 1983; 13:595-605

10. Domschke K \& Zwanzger P: GABAergic and endocannabinoid dysfunction in anxiety - future therapeutic targets? Curr Pharm Des 2008; 14:3508-17

11. Domschke K, Reif A, Weber H, Richter J, Hohoff C, Ohrmann $P$ et al: Neuropeptide $S$ receptor gene - converging evidence for a role in panic disorder. Mol Psychiatry 2011; 16:938-948

12. Domschke K: Patho-genetics of posttraumatic stress disorder. Psychiatr Danub 2012; 3:267-273

13. Donner J, Sipila T, Ripatti S, Kananen L, Chen X et al.: Support for involvement of glutamate decarboxylase 1 and neuropeptide $y$ in anxiety susceptibility. Am J Med Genet B Neuropsychiatr Genet 2012; 159:316-327

14. Džubur Kulenović A, Agani F, Avdibegović E, Jakovljević M, Babić D, Kučukalić A et al.: Molecular Mechanisms of Posttraumatic Stress Disorder (PTSD) as a Basis for Individualized and Personalized Therapy: Rationale, Design and Methods of the South Eastern Europe (SEE)PTSD study. Psychiatr Danub 2016; 28:154-63

15. Gillespie CF, Bradley B, Mercer K, Smith AK, Conneely $K$, Gapen $M$ et al.: Trauma exposure and stress-related disorders in inner city primary care patients. Gen Hosp Psychiatry 2009; 31:505-514

16. Goddard AW, Mason GF, Appel M, Rothman DL, Gueorguieva $R$, Behar $K L$ et al.: Impaired GABA neuronal response to acute benzodiazepine administration in panic disorder. Am J Psychiatry 2004; 161:2186-93

17. Goenjian AK, Bailey JN, Walling DP, Steinberg AM, Schmidt D, Dandekar $U$ \& Noble EP: Association of TPH1, TPH2, and 5HTTLPR with PTSD and depressive symptoms. J Affect Disord 2012; 140:244-52

18. Gillespie CF, Phifer J, Bradley B \& Ressler KJ: Risk and resilience: genetic and environmental influences on development of the stress response. Depress Anxiety 2009; 26: 984-992

19. Gottesman II \& Gould TD: The endophenotype concept in psychiatry: etymology and strategic intentions. Am J Psychiatry 2003; 160:636-645

20. Glotzbach-Schoon E, Andreatta M, Reif A, Ewald H, Tröger C, Baumann $C$ et al.: Contextual fear conditioning in virtual reality is affected by 5HTTLPR and NPSRI polymorphisms: effects on fear-potentiated startle. Front Behav Neurosci 2013; 7:31

21. Ham BJ, Sung Y, Kim N, Kim SJ, Kim JE, Kim DJ et al.: Decreased GABA levels in anterior cingulate and basal ganglia in medicated subjects with panic disorder: a proton magnetic resonance spectroscopy (1H-MRS) study. Prog Neuropsychopharmacol Biol Psychiatry 2007; 31:403-11

22. Heike Weber et al.: Gender Differences in Associations of Glutamate Decarboxylase 1 Gene (GAD1) Variants with Panic Disorder. PLoS One 2012; 7:e37651

23. Hettema JM, An SS, Neale MC, Bukszar J, van den Oord EJ, Kendler KS et al.: Association between glutamic acid decarboxylase genes and anxiety disorders, major depression, and neuroticism. Mol Psychiatry 2006; 11:752-762

24. Howe AS, Buttenschon HN, Bani-Fatemi A, Maron E, Otowa T, Erhardt A et al.: Candidate genes in panic disorder: meta-analyses of 23 common variants in major anxiogenic pathways. Mol Psychiatry 2016; 21: 665- 679

25. Jakovljevic M, Brajkovic L, Jaksic N, Loncar M, AukstMargetic $B$ \& Lasic D: Posttraumatic stress disorders (PTSD) from different perspectives: a transdisciplinary integrative approach. Psychiatr Danub 2012; 24:246-55

26. Jakovljevic M: Resilience, psychiatry and religion from public and global mental health perspective: Dialogue and Cooperation in the Search for Humanistic Self, Compassionate Society and Empathic Civilization. Psychiatr Danub 2017; 29:238-244

27. Klumpers F, Heitland I, Oosting RS, Kenemans JL \& Baas JMP: Genetic variation in serotonin transporter function affects human fear expression indexed by fear-potentiated startle. Biol Psychol 2012; 89:277-282

28. Kessler RC \& Wang PS: The descriptive epidemiology of commonly occurring mental disorders in the United States. Annu Rev Public Health 2008; 29:115-129

29. Koenen KC, Moffitt TE, Caspi A, Gregory A, Harrington $H$ \& Poulton R: The Developmental Mental-Disorder Histories of Adults With Posttraumatic Stress Disorder: A Prospective Longitudinal Birth Cohort Study. J Abnorm Psychol 2008; 117:460-466

30. Koenen KC, Duncan LE, Liberzon I \& Ressler KJ: From candidate genes to genome-wide association: The challenges and promise of posttraumatic stress disorder genetic studies. Biol Psychiatry 2013; 74:634-636

31. Lappalainen J, Sanacora G, Kranzler HR, Malison R, Hibbard ES, Price LH et al.: Mutation screen of the glutamate decarboxylase-67 gene and haplotype association to unipolar depression. Am J Med Genet 2004; 124B:81-86

32. Leen-Feldner EW, Feldner MT, Knapp A, Bunaciu L, Blumenthal $H \&$ Amstadter AB: Offspring psychological and biological correlates of parental posttraumatic stress: review of the literature and research agenda. Clin Psychol Rev 2013; 33:1106-1133

33. Lonsdorf TB, Weike AI, Nikamo P, Schalling M, Hamm A \& Öhman A: Genetic gating of human fear learning and extinction: Possible implications for gene-environment interaction in anxiety disorder. Psychol Sci 2009; 20:198-206

34. Lundorf MD et al.: Mutational screening and association study of glutamate decarboxylase 1 as a candidate susceptibility gene for bipolar affective disorder and schizophrenia. Am J Med Genet B Neuropsychiatr Genet 2005; 135B:94-101

35. Meyer-Lindenberg A \& Weinberger DR: Intermediate phenotypes and genetic mechanisms of psychiatric disorders. Nat Rev Neurosci 2006; 7:818-827

36. Mineka $S$ \& Oehlberg $K$ : The relevance of recent developments in classical conditioning to understanding the etiology and maintenance of anxiety disorders. Acta Psychol 2008; 127:567-580 
37. Marenco S, Savostyanova AA, van der Veen JW, Geramita $M$, Stern A et al.: Genetic modulation of GABA levels in the anterior cingulate cortex by GAD1 and COMT. Neuropsychopharmacology 2010; 35:1708-1717

38. Nemeroff $C B$ : The role of GABA in the pathophysiology and treatment of anxiety disorders. Psychopharmacol Bull 2003; 37:133-146

39. Orr SP, Metzger LJ, Lasko NB, Macklin ML, Peri $T \&$ Pitman RK: De novo conditioning in trauma-exposed individuals with and without posttraumatic stress disorder. J Abnorm Psychol 2000; 109:290-298

40. Okamura N, Hashimoto K, Iyo M, Shimizu E, Dempfle A, Friedel $S$ \& Reinscheid RK: Gender-specific association of a functional coding polymorphism in the Neuropeptide $S$ receptor gene with panic disorder but not with schizophrenia or attention-deficit/hyperactivity disorder. Prog Neuropsychopharmacol Biol Psychiatry 2007; 31:1444-1448

41. Roy-Byrne PP: The GABA-benzodiazepine receptor complex: structure, function, and role in anxiety. $J$ Clin Psychiatry 2005; 66:14-20

42. Roy-Byrne PP, Cowley DS, Hommer D, Greenblatt DJ, Kramer GL \& Petty F: Effect of acute and chronic benzodiazepines on plasma GABA in anxious patients and controls. Psychopharmacology (Berl) 1992; 109:153-156

43. Raczka KA, Gartmann N, Mechias ML, Reif A, Büchel C, Deckert $J$ et al.: A neuropeptide $S$ receptor variant associated with overinterpretation of fear reactions: a potential neurogenetic basis for catastrophizing. Mol Psychiatry 2010; 15:1067-1074
44. Pape HC, Jüngling $K$, Seidenbecher $T$, Lesting $J \&$ Reinscheid RK: Neuropeptide S: a transmitter system in the brain regulating fear and anxiety. Neuropharmacology 2010; 58:29-34

45. Sheerin CM, Lind MJ, Bountress KE, Nugent NR \& Amstadter AB: The genetics and epigenetics of PTSD: overview, recent advances, and future directions. Curr Opin Psychol 2017; 14:5-11

46. Vitale $G$, Filaferro $M$, Ruggieri V, Pennella $S$, Frigeri $C$, Rizzi A et al.: Anxiolytic-like effect of neuropeptide $S$ in the rat defensive burying. Peptides 2008; 29:2286-2291

47. Weber H, Scholz CJ, Domschke K, Baumann C, Klauke B, Jacob CP et al.: Gender differencesin associations of glutamate decarboxylase 1 gene (GAD1) variants with panic disorder. PLoS One 2012; 7:37651

48. Weiss T, Skelton K, Phifer J, Jovanovic T, Gillespie CF, Smith A, Umpierrez G, Bradley B \& Ressler KJ. Posttraumatic stress disorder is a risk factor for metabolic syndrome in an impoverished urban population. Gen Hosp Psychiatry 2011; 33:135-142

49. Weiss T, Skelton K, Phifer J, Jovanovic T, Gillespie CF, Smith A et al.: Post-traumatic stress disorder is a risk factor for metabolic syndrome in an impoverished urban population. Gen Hosp Psychiatry 2011; 33:135-142

50. Xu YL, Reinscheid RK, Huitron-Resendiz S, Clark SD, Wang Z, Lin SH et al.: Neuropeptide S: a neuropeptide promoting arousal and anxiolytic-like effects. Neuron 2004; 43:487-497

51. Zwanzger P \& Rupprecht: Selective GABAergic treatment for panic? Investigations in experimental panic induction and panic disorder. J Psychiatry Neurosci 2005; 30:167-175

Correspondence:

Valdete Haxhibeqiri, $M D$

Department of Clinical Biochemistry, University Clinical Centre of Kosovo

Bregu i Diellit, Blloku 10, no. 4, Prishtina, Republic of Kosova

E-mail:valbera@yahoo.com 